\title{
Rehabilitation of the Hospice and Palliative Care Patient
}

\author{
Noel S.C. Javier, M.D.' and Marcos L. Montagnini, M.D., FACP ${ }^{2,3}$
}

\begin{abstract}
Disability is a common problem among hospice and palliative care patients. It leads to depression, poor quality of life, increased caregiver needs, health care resource utilization, and need for institutionalization. There is a growing body of evidence that rehabilitation interventions improve functional status, quality of life, and symptoms such as pain and anxiety in this population. Having adequate knowledge about rehabilitation is essential for the provision of comprehensive end-of-life care. The goals of this article are to review the role and benefits of rehabilitation in hospice and palliative care; to discuss the elements of patient assessment for rehabilitation including the use of functional assessment tools; and to review the roles of physical, occupational, and speech therapy in hospice and palliative care patients.
\end{abstract}

\section{Introduction}

W ITH DISEASE PROGRESSION, hospice and palliative care patients experience high levels of functional loss, dependency for activities of daily living (ADLs), and mobility dysfunction. ${ }^{1-2}$ Disability in these patients is related to multiple factors that include deconditioning, fatigue, complications from therapies, undernutrition, neurologic and musculoskeletal problems, pain, bowel and bladder dysfunction, thromboembolic disease, depression, and coexisting comorbidities. ${ }^{1-8}$ Lehmann and colleagues ${ }^{4}$ documented that in the hospital setting, 35\% of cancer patients experienced functional loss due to physical weakness, 32\% required assistance with performance on ADLs, 23\% experienced difficulty with ambulation, and $7 \%$ had deficits in transfers. Yoshioka $^{3}$ and Sabers and associates ${ }^{5}$ also described significant functional impairments in patients with advanced and terminal cancer.

Physical disability affects most aspects of life and leads to depression, poor quality of life, increased caregiver needs, health care resource utilization, and need for institutionalization. ${ }^{1,9-11}$ Physical strength, hours spent in bed, and the ability to do what one wants are important indicators of quality of life for cancer patients and their spouses. ${ }^{1-2,8,12}$ Progressive debility and being a burden to others have been cited by Breitbart and colleagues ${ }^{13}$ and Morita and associates $^{14}$ as reasons for desiring death among cancer patients. A study by Emanuel et al. identified the perception of increasing dependency as a strong predictor of patients' interest in physician-assisted suicide. ${ }^{15}$
The concept of rehabilitation in hospice and palliative care is gaining more attention in the literature. Most hospice and palliative care patients express a desire to remain physically independent during the course of their disease. ${ }^{3,16-18}$ Maintaining the highest level of functional ability, particularly mobility, for as long as possible is one of the benefits that rehabilitative therapy can offer to this population. ${ }^{17}$ Moreover, rehabilitation can reduce the burden of care for families and caregivers, improve patients' overall quality of life, satisfaction of care, functional status, pain, and anxiety. ${ }^{1-3,5-7,19-23}$

\section{Objectives}

The objectives of this article are to review the concept and the benefits of rehabilitation in hospice and palliative care, to review patient evaluation and functional assessment tools, and to discuss the role of the interdisciplinary rehabilitation team in treating hospice and palliative care patients.

\section{The Concept of Rehabilitation in Hospice and Palliative Care}

The concept of rehabilitation is based on function, which refers to an individual's ability to complete daily survival tasks. Rehabilitation is the process of helping a person to reach the fullest physical, psychological, social, vocational, and educational potential consistent with his or her physiological or anatomical impairment, environmental limitations, desires, and life plans. ${ }^{2,24}$ Impairment is defined as the loss or abnormality of psychological, physiological, or anatomical structure or function resulting from pathology, whereas

\footnotetext{
${ }^{1}$ Division of Geriatrics, Department of Medicine, Warren Alpert Medical School, Brown University, Providence, Rhode Island.

${ }^{2}$ Division of Geriatric Medicine, Department of Internal Medicine, University of Michigan, Ann Arbor, Michigan.

${ }^{3}$ VA Ann Arbor Geriatrics Research Education and Clinical Center (GRECC), Ann Arbor, Michigan.

Accepted December 22, 2010.
} 
disability refers to any restriction or lack of ability to perform an activity in the manner or within range considered normal for a human being. ${ }^{25}$ The concept of palliative rehabilitation is derived from Dietz's concept of cancer rehabilitation according to disease staging, as follows: preventative, restorative, supportive, and palliative. ${ }^{20,23}$ Preventative rehabilitation attempts to preclude or mitigate functional morbidity caused by cancer or its treatment. Restorative rehabilitation refers to the effort to return patients to their premorbid functional status when little or no long-term impairment is anticipated. Supportive rehabilitation attempts to maximize function after permanent impairments caused by cancer and/or its treatment. Palliative rehabilitation's primary goal is the reduction of dependence in mobility and self-care activities in association with the provision of comfort and emotional support.

Patients with progressive and oftentimes irreversible diseases often have symptomatic problems such as pain, decreased endurance, orthostatic intolerance, dysphagia, and skin breakdown, among others that can potentially respond to supportive and palliative rehabilitation strategies. ${ }^{2,11,26}$

\section{Benefits of Palliative Rehabilitation}

Several studies document the benefits of rehabilitation in patients with advanced cancer, cardiac, and lung disease (Table 1).

Yoshioka ${ }^{3}$ found that hospice patients who received rehabilitation had improved quality of life, mobility, and symptoms such as pain, dyspnea, and leg edema. In two separate studies using comprehensive inpatient rehabilitation for cancer patients, Sabers et al. ${ }^{5}$ demonstrated improvement in pain, mood, and mobility, whereas Marciniak and associates ${ }^{6}$ found significant functional gains in all cancer subgroups including those with metastases. Montagnini et al. ${ }^{24}$ supported findings that inpatient physical therapy benefited $56 \%$ of palliative care patients whose ADL scores improved within 2 weeks and after completion of the program. Scialla and colleagues $^{\prime 21}$ retrospective study of older patients with cancer asthenia revealed statistically significant gains in motor and cognitive function from admission to discharge. Cole et al.' $\mathrm{s}^{7}$ study of 200 cancer patients who underwent comprehensive inpatient rehabilitation showed improvement in both motor and cognitive functions with the exception of those with intracranial neoplasm, who had only a notable improvement in motor function. In contrast, Huang and associates ${ }^{27}$ casecontrolled retrospective study concluded that brain tumor patients can achieve outcome and rates of discharge comparable to community and have a shorter rehabilitation length of stay than stroke patients. Another study by O'Dell et al. ${ }^{28}$ documented that daily functional gains made by patients with brain tumors who are undergoing rehabilitation were similar to those patients with traumatic brain injury. Two small exercise intervention studies demonstrated some benefit on hospice and palliative care patients. Porock and colleagues' ${ }^{29}$ 28-day exercise program showed improvement in fatigue, anxiety, and quality of life for 9 hospice patients, whereas Oldervoll et al.'s ${ }^{30}$ 6-week structured physical exercise program demonstrated improvements in physical performance, fatigue, and quality of life in 34 hospice and palliative care cancer patients. Furthermore, cardiopulmonary rehabilitation has been studied in patients with advanced chronic obstructive pulmonary disease (COPD) and congestive heart failure
(CHF). Guell et al. ${ }^{31}$ demonstrated that inpatient pulmonary rehabilitation may decrease psychosocial morbidity in severe COPD patients in addition to confirming the positive impact on exercise capacity and quality of life. Resqueti and associates $^{32}$ found that home-based pulmonary rehabilitation in severe COPD patients led to improvements in exercise tolerance and quality of life that were maintained at 6 months. Freimark et al.'s ${ }^{33}$ study involving CHF patients demonstrated improvement in the functional and hemodynamic parameters following a hospital-based supervised exercise and rehabilitation program.

\section{Planning Rehabilitation}

Ideally, the rehabilitation plan should be developed by an interdisciplinary team led by a physiatrist experienced in hospice and palliative medicine and comprised of members from physical therapy, occupational therapy, speech therapy, psychology, nursing, nutrition, respiratory therapy, recreational therapy, and case management. ${ }^{34}$ The plan should be individualized and based on the patient's overall prognosis, potential to regain function, and desire and motivation to participate in the program.

Rehabilitation can be provided in the inpatient, outpatient, and home settings. Inpatient acute rehabilitation is designed for patients who have the potential for significant functional improvement, and are able to tolerate at least 3 hours of daily therapy five times per week. ${ }^{35,36}$ In contrast, subacute inpatient rehabilitation offers coordinated interdisciplinary services to patients with less intense rehabilitation needs who can tolerate at least 1 hour of therapy each day. It may also serve as a transitional program before discharge from medical and surgical units and for respite or palliative care. ${ }^{37}$ Outpatient rehabilitation offers comprehensive interdisciplinary or single rehabilitation services for patients living in the community. Most home care agencies can provide physical therapy, occupational therapy, speech therapy, social work, and skilled nursing care to homebound patients. Hospice programs may provide physical, occupational, and speech-language therapy in the inpatient as well as the home environment.

Discharge planning is an integral component of any rehabilitation program across various settings. It is a dynamic interdisciplinary process that should take into consideration the patient's progress toward meeting the preestablished rehabilitation goals, the degree of caregiver support needed after the rehabilitation program, and the setting in which the patient will receive care.

Rehabilitation services in the inpatient, outpatient, and home settings are covered by Medicare, Medicaid, and most private insurance companies according to their specific criteria for reimbursement. Patients enrolled in the Medicare hospice benefit are eligible to receive physical, occupational, and speech-language therapy as well as adaptive equipment without additional cost. ${ }^{38}$

\section{Patient Assessment}

A thorough patient assessment is essential for rehabilitation planning and should include information on disease location, staging, previous and current therapies, estimated life expectancy, comorbidities, pain and nonpain symptoms, 
medications, cognition, mood, nutrition, and physical function. Assessment of home and community support systems as well as financial resources is also important. A complete physical examination with special attention to the neurological and musculoskeletal systems is essential in determining motor strength, joint flexibility, gait pattern, and fall risk. Several functional assessment scales may be utilized in hospice and palliative care patients as follows:

The Karnofsky Performance Scale (KPS) is a functional assessment tool developed for cancer patients that consists of a 100-point scale of general function corresponding to the patient's ability to live at home and/or the need for institutionalization. ${ }^{28-29}$ It is also used for prognostication in hospice and palliative care. ${ }^{39-40}$

The Palliative Performance Scale (PPS) is an observer-rated assessment scale of ambulation, activity level, self-care, oral intake, and level of consciousness that is useful in identifying potential care needs for the palliative care patient. It is a reliable and valid tool that correlates well with the survival time of cancer patients. ${ }^{41}$

The Eastern Cooperative Oncologic Scale (ECOG) developed for cancer patients is utilized for prognostication in hospice and palliative care. This is a 5-point scale that assesses the patient's ability to walk, care for self, and the need for dependence on others. ${ }^{42}$

The Edmonton Functional Assessment Tool (EFAT) consisting of two parts is designed and validated for the palliative care population. ${ }^{43-45}$ The first part includes 10 items scored on a 4point rating scale ( 0 to 4 ). These items include communication, mental status, pain, respiratory function, sitting or standing balance, mobility, walking or wheelchair locomotion, ADL, fatigue, and motivation. The second part is a single overall rating of the patient's functional status on a 4-point scale (0 to 4$)$.

The Katz Activities of Daily Living ${ }^{46,47}$ was originally developed for the chronically ill and the aged, but is also commonly used to assess the functional status of hospice and palliative care patients. It consists of six domains that include bathing, dressing, toileting, transferring, continence, and feeding. Each category is rated as dependent (0) or independent (1).

The Lawton Instrumental Activities of Daily Living ${ }^{48-49}$ measures eight domains of function that include medication management, telephone use, housekeeping, food preparation, laundry, financial management, transportation, and shopping. It is most useful for identifying how a person is functioning at the present time and to identify improvement or deterioration over time.

The Barthel Index $x^{3,50-51}$ assesses the patient's independence in performing ADLs. The 10 items of this scale include feeding, dressing, personal hygiene, bowel control, bladder control, wheelchair transfer to and from bed, toilet transfer, bathtub transfer, walking on level or being propelled by wheelchair, and ascending and descending stairs.

The Functional Independence Measure (FIM) is a comprehensive observer-rated scale that contains 18 items rated on 7level ordinal scale with a score of 1 requiring total assistance and 7 with full independence. The items include self-care (6 items), sphincter control (2 items), mobility (3 items), locomotion (2 items), communication (2 items), and social cognition ( 3 items). It is a reliable and valid tool measuring functional outcomes in rehabilitation settings. $5,7,21,52-53$
For fall risk assessment, the Berg Balance Scale and Tinetti Assessment of Balance and Gait are commonly used. Both are performance-based instruments.

The Berg Balance Test ${ }^{54}$ assesses 14 tasks generally related to changes in position from sitting to standing, transfers, reaching with outstretched arm, turning, and standing with one foot.

The Tinetti Assessment of Balance and Gait ${ }^{55}$ has nine items for balance and seven items for gait. The items for balance include sitting balance, arising, attempts to arise, immediate standing balance within 5 seconds, standing balance, being nudged, eyes closed, turning 360 degrees, and sitting down. The items for gait include initiation of gait, step length and height, step symmetry, step continuity, path walked, trunk, and walking stance.

The Timed Up and Go (TUG) test ${ }^{56-57}$ is a performance assessment tool used in the elderly population. The patient is asked to stand without using proximal muscles if possible from a sitting position and asked to walk 3 meters forward and come back to a sitting position. The average normal time to complete the task is about 10 seconds. If the time to finish the task is greater than 20 seconds, that patient has a strong likelihood of falling.

The 6 Minute Walk Test $(6 M W T)^{58}$ is a self-paced endurance assessment in which the patient is scored in his or her ability to walk in 6 minutes. The 6MWT is a useful measure of functional capacity and is widely used for measuring response to rehabilitation interventions for pulmonary and cardiac disease. Table 2 outlines the scoring system for each tool.

\section{Role of Physical Therapy}

Table 3 adapted from Frost highlights the functional tasks evaluated by the physical therapist. ${ }^{59}$ Specific interventions utilized by physical therapy include physical modalities for pain control, provision of adaptive and assistive equipment, environmental modification, education on energy conservation, and exercise. ${ }^{60}$ Examples of physical modalities used to treat pain include massage, heat, cold, ultrasound, transcutaneous electrical nerve stimulation (TENS), diathermy, manual lymphatic drainage, and soft tissue mobilization. ${ }^{61}$ Adaptive equipment is used to improve performance in ADLs. ${ }^{34,62}$ Examples include reachers, rocker knives, onehanded cutting boards, and sandwich holders for assistance with cooking and eating. Assistive devices are prescribed to help with ambulation, mobility, balance, pain, fatigue, weakness, joint instability, excessive skeletal loading, and elimination of weight-bearing on an affected extremity. Examples include crutches, canes, walkers, wheelchairs, and scooters for mobility, and lifts, ramps, and transfer boards for facilitation with transfers. Orthotics can be helpful in enhancing joint stability and safety for patients with motor deficits. ${ }^{1}$ Examples include truncal orthotics for osseous instability, upper extremity orthotics to assist with manipulation of objects, and lower extremity orthotics to promote joint stability and muscle function for safe ambulation.

Environmental modification is another important intervention by physical therapy. ${ }^{59}$ Some examples include placing a recliner on a platform to assist in transfer, having a high stool in the kitchen to reach a cupboard, and adjusting the height and arms of the chair to assist in transfer. The therapist 


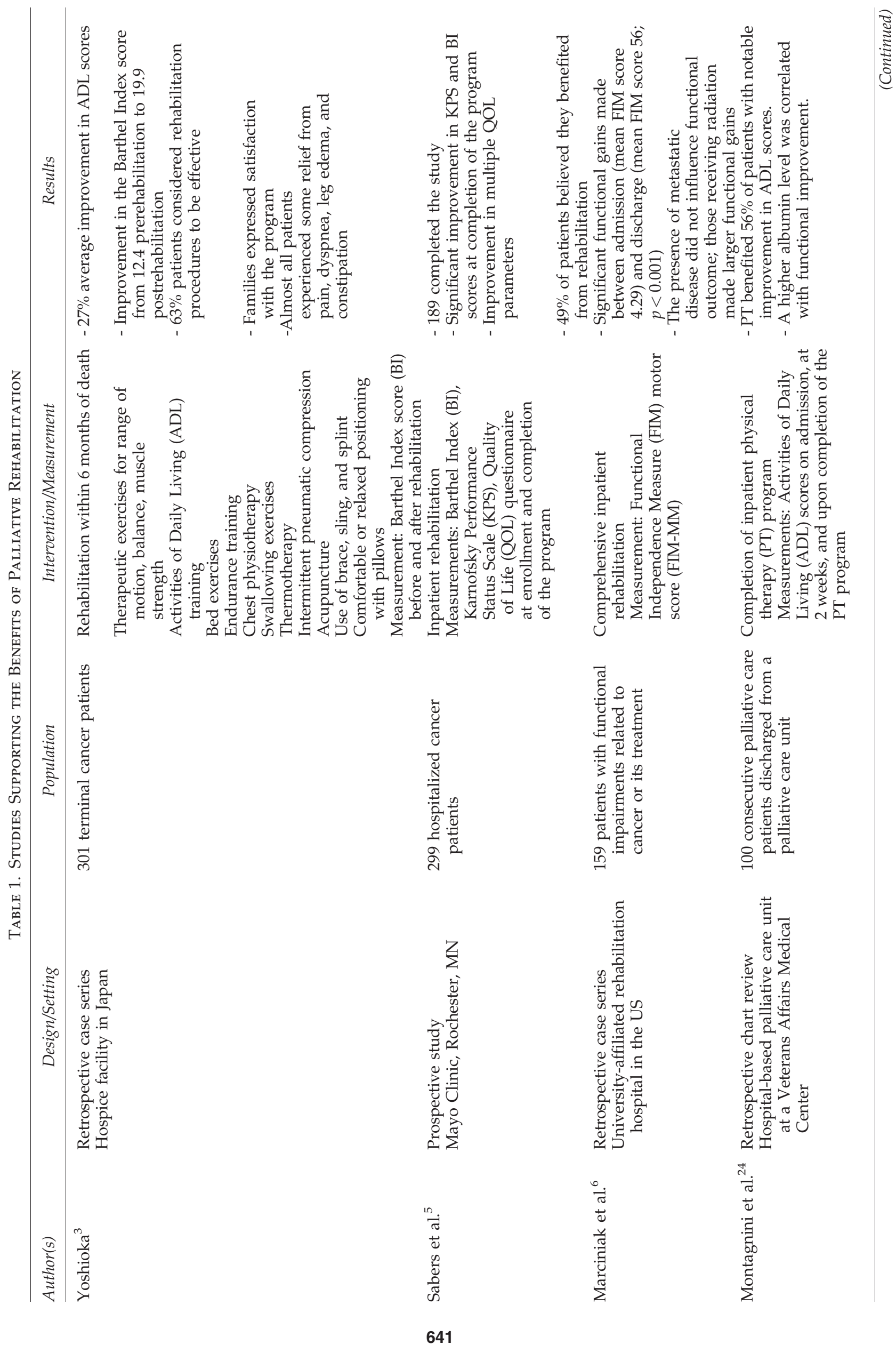




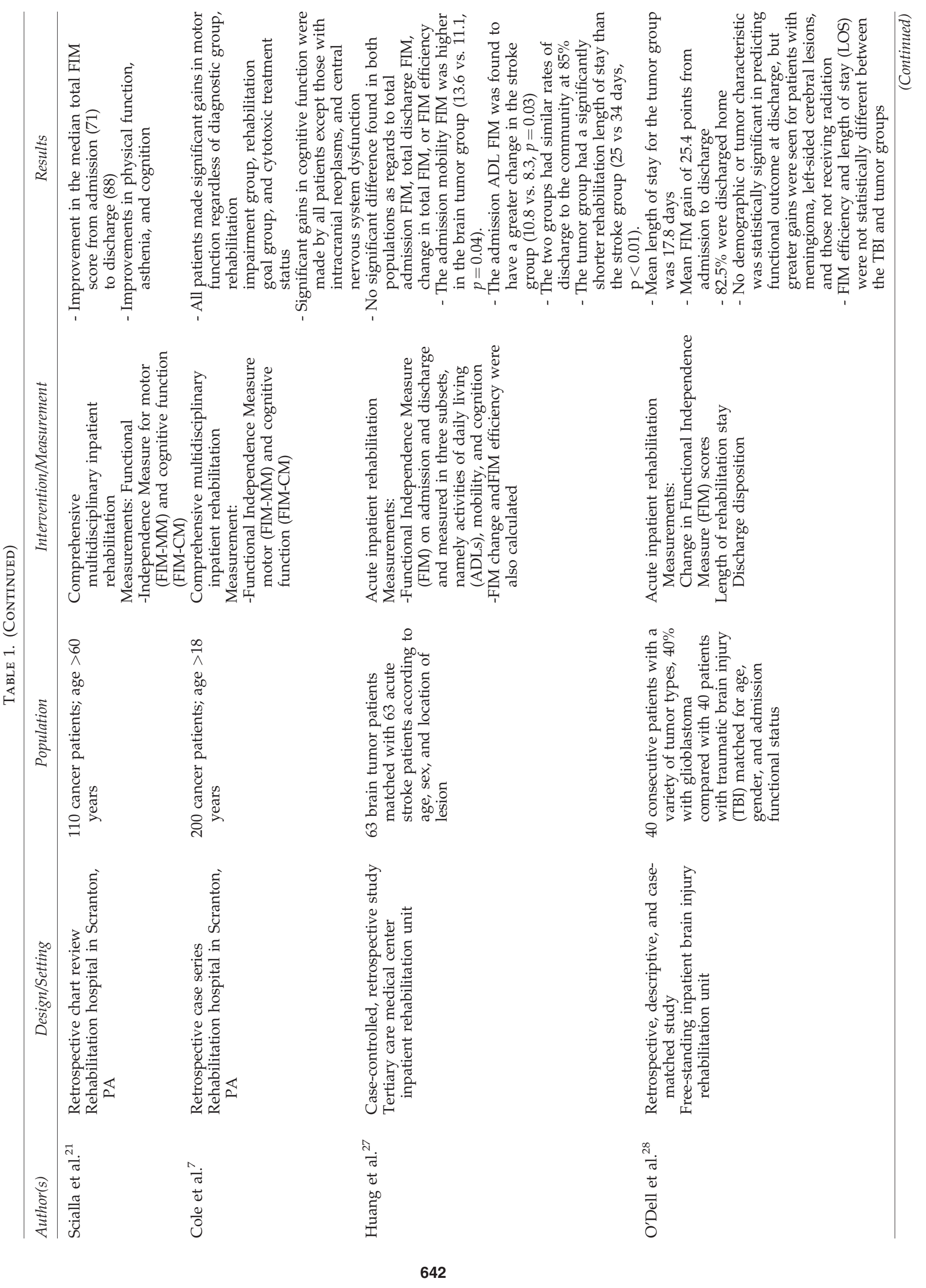




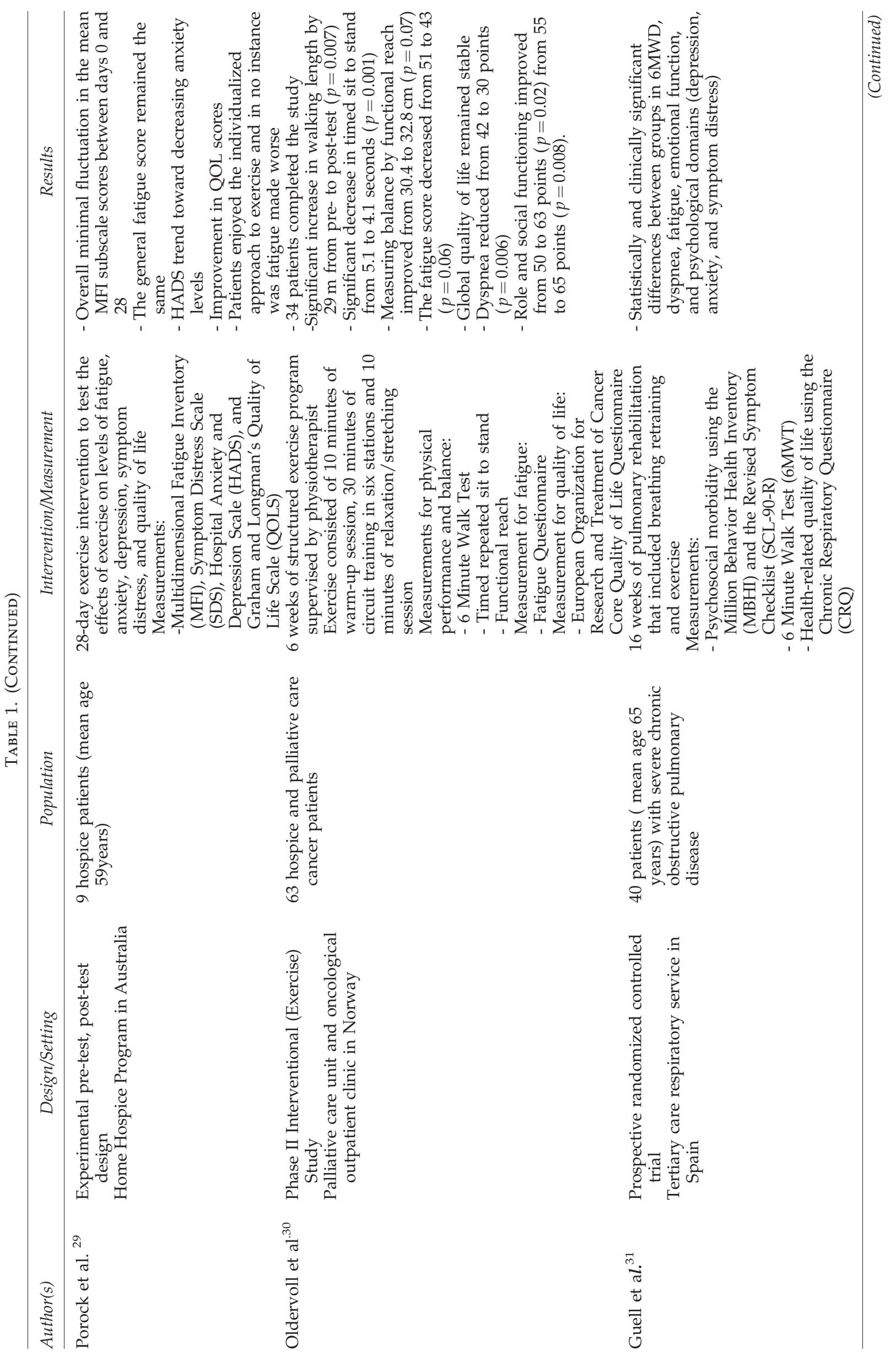




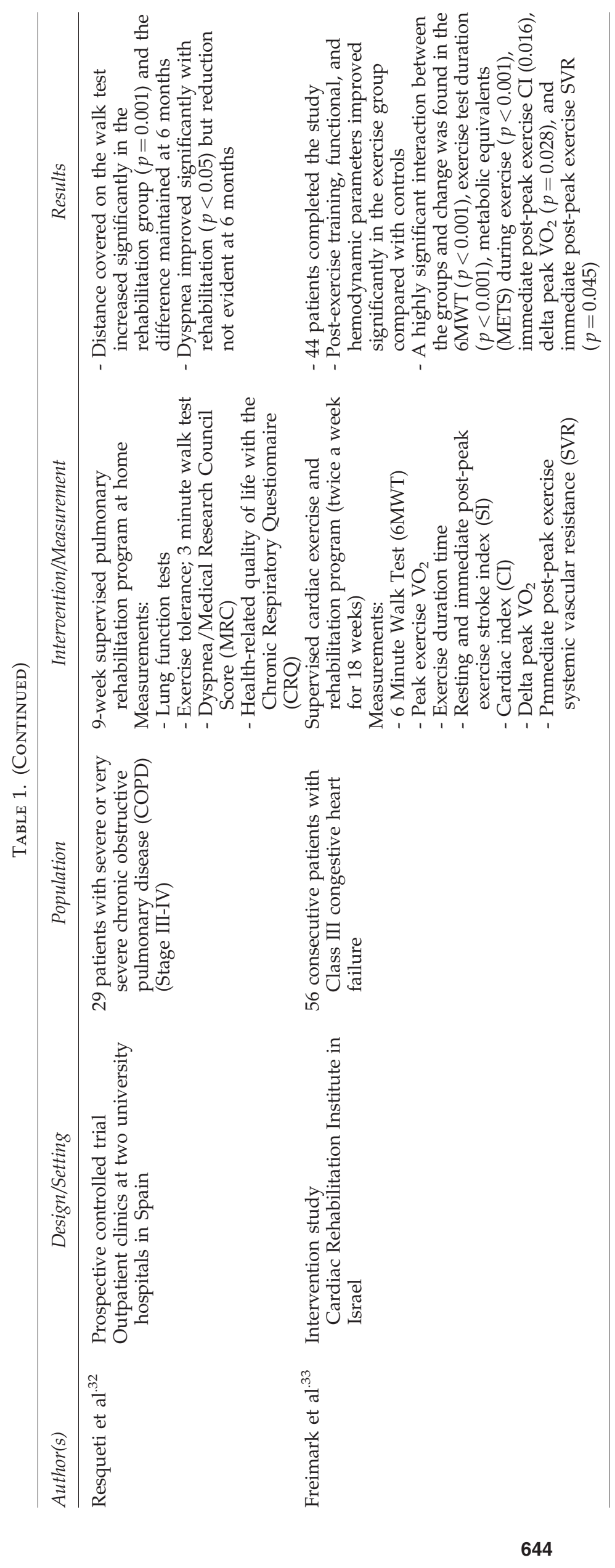


Table 2. Functional Assessment Tools

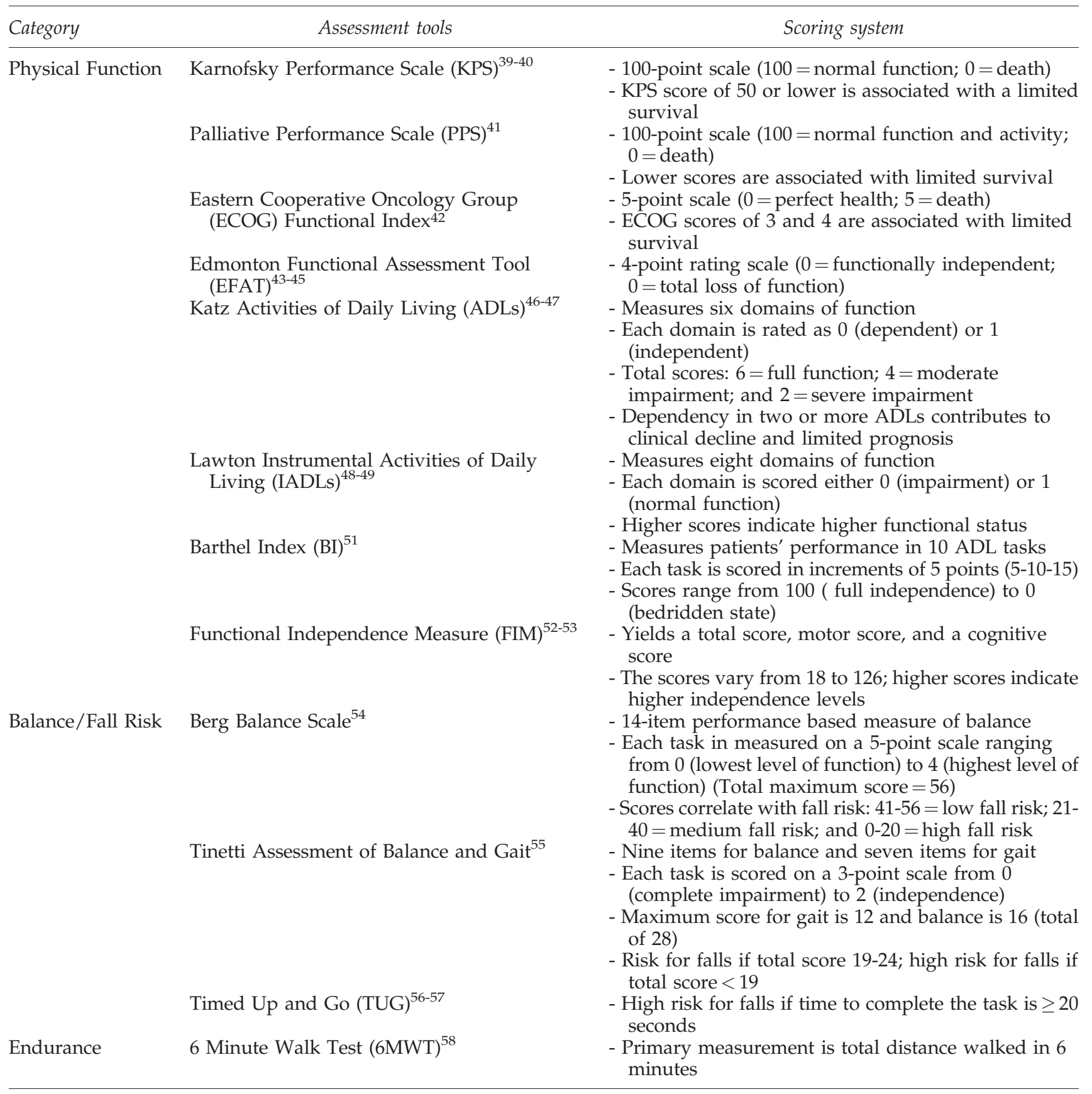

can also teach the patient energy management and conservation such as monitoring of fatigue levels and guidance on rest periods. The therapist can play an active role in caregiver education and support to include instructions on the use of equipment, use of good body mechanics, and utilization of strategies to prevent falls and maintain balance. Physical therapists use exercise in the maintenance of muscle strength, joint flexibility, range of motion, and balance. ${ }^{2,61}$ In general, the types of exercise include passive, active, active-assisted, resistive, progressive resistive, stretching, and aerobic. ${ }^{2,61}$ The positive effects of exercise in patients with advanced diseases include improvements in the physiological and psychological functional parameters such as functional capacity, body composition, mood, self-esteem, quality of life, and problems such as fatigue, nausea, pain, muscle spasm, and edema. ${ }^{2,28-30}$

Reconditioning programs for patients with advanced cancer, cardiac, and lung diseases include graded aerobic and stretching exercises to increase cardiopulmonary capacity and endurance. ${ }^{63}$ Stationary devices such as treadmills, ergometers, and rowing machines are used for aerobic exercise training. In addition to aerobic exercise, pulmonary rehabilitation programs also include interventions such as inspiratory muscle retraining, noninvasive mechanical ventilation, education on oxygen consumption, breathing techniques, 
Table 3. Functional Tasks Addressed By Physical Therapy

\begin{tabular}{ll}
\hline Functional task & \multicolumn{1}{c}{ Components/Description } \\
\hline Bed mobility & - Rolling (supine to side lying - right \\
and left) & - Positioning for comfort \\
& - Positioning for pressure relief \\
& - Bridging (lifting pelvis off the bed) \\
& - Supine to sit \\
& - Sit to supine \\
& - Set up (i.e., positioning of \\
& wheelchair in relation to bed) \\
& - Sit to stand \\
Transfers & - Pivot (or slide) \\
& - Stand to sit \\
& - Assistive device placement \\
Ambulation or gait & - Gait assessment \\
& - Foot placement \\
\hline
\end{tabular}

Source: Frost M: The role of physical, occupational, and speech therapy in hospice: Patient empowerment. Am J Hosp Palliat Care 2001;18:397-402. (Adapted with permission.)

postural drainage, management of secretions, and relaxation techniques. ${ }^{64}$

\section{Role of Occupational Therapy}

The National Council for Hospice and Specialist Palliative Care Services in 2000 valued the importance of occupational therapy in the rehabilitation of oncology and palliative care patients. ${ }^{65}$ The occupational therapist assesses and provides treatment programs in the functional areas such as ADLs, work tasks, self-esteem, employment, role-related tasks, recreation, use of adaptive equipment, as well as discharge planning. Table 4 highlights the ADLs addressed by the occupational therapist. ${ }^{59}$

Specific interventions include home assessment, prescription of equipment, coaching in personal and domestic tasks, education strategies for symptom control, relaxation, stress management, facilitation of social and leisure activities, and provision of information and support for caregivers. ${ }^{66}$

\section{Role of Speech and Language Therapy}

Pollens has identified four roles of the speech-language therapy in end-of-life care. ${ }^{67}$ First, to provide consultation to patients, families, and the hospice team in the areas of communication, cognition, and swallowing function. Second, to develop strategies in the area of communication skills to support the patient's role in decision making, maintain social closeness, and to assist the patient in the fulfillment of end-of-life goals. ${ }^{68,69}$ Third, to assist in optimizing function related to dysphagia symptoms to improve patient comfort and satisfaction and promote positive feeding interactions with family members. Fourth, to communicate with the hospice team in the provision and acknowledgment of input related to overall patient care.

Speech-language therapy addresses functional tasks involving the oral-pharyngeal-laryngeal function and the cognitive components in the communication process. ${ }^{59}$ Table 5 outlines the areas addressed by the speech therapist.
Table 4. Functional Tasks Addressed By OCCUPATIONAL THERAPy

\begin{tabular}{ll} 
Functional task & \multicolumn{1}{c}{ Components/Description } \\
\hline Self-care & - Bathing \\
& - Dressing \\
& - Grooming \\
& - Toileting \\
& - Self-feeding \\
Transfers (as they & - Shower or tub transfers \\
relate to ADL or & - Toilet transfers \\
home management) & - Retrieving objects from the floor, \\
& cupboards, high shelves \\
& - Carrying objects \\
Home management & - Food preparation \\
& - Managing faucets, lights, doors, \\
& drawers \\
& - Use of remote controls, phone, \\
& home appliances \\
& - Food management (grocery list \\
& compilation, grocery shopping) \\
& - Social management \\
(transportation, calendar, & communications) \\
& - Money management
\end{tabular}

Source: Frost M: The role of physical, occupational, and speech therapy in hospice: Patient empowerment. Am J Hosp Palliat Care 2001;18:397-402. (Adapted with permission.)

Table 5. Functional Tasks Addressed BY SPEECH THERAPY

\begin{tabular}{|c|c|}
\hline Functional Task & Components/Description \\
\hline Receiving information & $\begin{array}{l}\text { - Auditory comprehension } \\
\text { - Visual comprehension } \\
\text { - Reading comprehension }\end{array}$ \\
\hline $\begin{array}{l}\text { Communicating } \\
\text { information } \\
\text { (expressing needs) }\end{array}$ & $\begin{array}{l}\text { - Verbal expression } \\
\text { - Nonverbal and graphic expression } \\
\text { - Speech intelligibility } \\
\text { - Voice quality and volume } \\
\text { - Prosody (change in pitch, stress, } \\
\text { intensity, and duration of sound) } \\
\text { - Latency of response }\end{array}$ \\
\hline Oral motor function & $\begin{array}{l}\text { - Tongue coordination } \\
\text { - Lip closure (loss of food or } \\
\text { drinking) } \\
\text { - Bolus control } \\
\text { - Transit time } \\
\text { - Food management (pocketing, } \\
\text { etc.)- Swallow reflex } \\
\text { - Cough or choke } \\
\text { - Vocal quality following intake } \\
\text { - Consistency of foods or liquids } \\
\text { tolerated (i.e., thin vs. thickened, } \\
\text { puree, soft, mechanical, or regular } \\
\text { solids) } \\
\text { - Presence of regurgitation }\end{array}$ \\
\hline
\end{tabular}

Source: Frost M: The role of physical, occupational, and speech therapy in hospice: Patient empowerment. Am J Hosp Palliat Care 2001;18:397-402. (Adapted with permission.) 


\section{Summary}

Progressive disability is common among hospice and palliative care patients. It leads to depression, poor quality of life, increased caregiver needs, health resource utilization, and need for institutionalization. Supportive and palliative rehabilitation interventions are intended to optimize function and comfort in these patients. Small retrospective studies have demonstrated some of the potential benefits of rehabilitation in this population. They include improvement in functional capacity, quality of life, mobility, fatigue, pain, well-being, dyspnea, emotional state, and cognitive function. Patient assessment for rehabilitation should be comprehensive and interdisciplinary. The treatment plan should be individualized and based on the patient's overall prognosis, potential to regain function, and desire and motivation to participate in the program. Several interventions can be used in supportive and palliative care rehabilitation programs, such as physical, occupational, and speech-language therapy. Having knowledge of the potential benefits of palliative rehabilitation is essential for the health care provider dealing with patients with lifelimiting diseases. Larger randomized controlled trials are also needed to further demonstrate the benefits of rehabilitation in this population.

\section{Author Disclosure Statement}

No competing financial interests exit.

\section{References}

1. Cheville AL: Rehabilitation of patients with advanced cancer. Cancer Suppl 2001;92:1039-1048.

2. Santiago-Palma J, Payne R: Palliative care and rehabilitation. Cancer Suppl 2001;92:1049-1052.

3. Yoshioka H: Rehabilitation for the terminal cancer patient. Am J Phys Med Rehabil 1994;73:199-206.

4. Lehmann JF, DeLisa JA, Warren CG, deLateur BJ, Bryant PL, Nicholson CG: Cancer rehabilitation: Assessment of need, development, and evaluation of a model of care. Arch Phys Med Rehabil 1978;59:410-419.

5. Sabers SR, Kokal JE, Girardi JC, Philpott CL, Basford JR, Therneau TM, Schmidt KD, Gamble GL.: Evaluation of consultation-based rehabilitation for hospitalized cancer patients with functional impairment. Mayo Clin Proc 1999;74:855-861.

6. Marciniak CM, Sliwa JA, Spill G, Heinemann AW, Semik PE: Functional outcome following rehabilitation of cancer patient. Arch Phys Med Rehabil 1996;77:54-57.

7. Cole RP, Scialla SJ, Bednarz L: Functional recovery in cancer rehabilitation. Arch Phys Med Rehabil 2000;81:623-637.

8. Jordhoy MS, Ringdal GI, Helbostad JL, Oldervoll L, Loge JH, Kaasa S: Assessing physical functioning: A systematic review of quality of life measures developed for use in palliative care. Palliat Med 2007;21:673-682.

9. Morris JN, Suissa S, Sherwood S, Wright SM, Greer D: Last days: a study of the quality of life of terminally ill cancer patients. J Chronic Dis 1986;39:47-62.

10. Curtis EB, Krech R, Walsh TD: Common symptoms in patients with advanced cancer. J Palliat Care 1991;7:25-29.

11. Donnelly S, Walsh D: The symptoms of advanced cancer. Semin Oncol 1995;22:67-72.

12. Axelsson B, Sjoden PO: Quality of life of cancer patients and their spouses in palliative home care. Palliat Med 1998;12:29-39.
13. Breitbart W, Chochinov H, Passik S: Psychiatric aspects of palliative care. In: Doyle D, Hanks G (eds): Oxford Textbook of Palliative Medicine. New York: Oxford University Press, 1998.

14. Morita T, Sakaguchi Y, Hirai K, Tsuneto S, Shima Y: Desire for death and requests to hasten death of Japanese terminally ill cancer patients receiving specialized inpatient palliative care. J Pain Symptom Manage 2004;27:44-52.

15. Emanuel E, Daniels ER, Fairclough DL: The practice of euthanasia and physician-assisted suicide in the United States. J of Am Med Assoc 1998;280:507-513.

16. Wallston KA, Burger C, Smith RA, Baugher RJ: Comparing the quality of death for hospice and non-hospice cancer patients. Med Care 1988;26:177-182.

17. Ebel S, Langer K: The role of the physical therapist in hospice care. Am J Hosp Palliat Care 1993;10:32-35.

18. Mayer N: Concepts in cancer rehabilitation. Semin Oncol 1975;2:393-398.

19. Nusbaum NJ: Rehabilitation and the older cancer patient. Am J Med Sci 1998;315:40-49.

20. Cheville AL: Cancer rehabilitation. Semin Oncol 2005;32:219224.

21. Scialla S, Cole R, Scialla T, Bednarz L, Scheerer J: Rehabilitation for elderly patients with cancer asthenia: Making a transition to palliative care. Palliat Med 2000;14: 121-127.

22. Olson E, Cristian A: The role of rehabilitation medicine and palliative care in the treatment of patients with end-stage disease. Phys Med Rehabil Clin N Am 2005;16:285-305.

23. Dietz JH: Rehabilitation of the cancer patient. Med Clin North Am 1969;53:607-624.

24. Montagnini M, Lodhi M, Born W: The utilization of physical therapy in a palliative care unit. J Palliat Med 2003;6:11-17.

25. Rondinelli R. Disability determination. In: DeLisa J, Gans B, Walsh N (eds): Physical Medicine and Rehabilitation: Principle $\mathcal{E}$ Practice, 4th ed. Philadelphia: Lippincott Williams and Wilkins, 2005, p.169.

26. Curtis EB, Krech R, Walsh TD: Common symptoms in patients with advanced cancer. J Palliat Care 1991;7:25-29.

27. Huang ME, Cifu DX, Keyser-Marcus L: Functional outcome after brain tumor and acute stroke: A comparative analysis. Arch Phys Med Rehabil 1998;79:1386-1390.

28. O’Dell MW, Barr K, Spanier D, Warnick R: Functional outcome of inpatient rehabilitation in persons with brain tumor. Arch Phys Med Rehabil 1998;79:1530-1534.

29. Porock D, Kristjanson LJ, Tinnelly K, Duke T, Blight J: An exercise intervention for advanced cancer patients experiencing fatigue: A pilot study. J Palliat Care 2000;16:30-36.

30. Oldervoll LM, Loge JH, Paltiel H, Asp MB, Vidvei U, Wiken AN, Hjermstad MJ, Kaasa S: The Effect of a physical exercise program in palliative care: A phase II study. J Pain Symptom Manage 2006;31:421-430.

31. Guell R, Resqueti V, Sangenis M, Morante F, Martorell B, Casan P, Guyatt G: Impact of pulmonary rehabilitation on psychosocial morbidity in patients with severe COPD. Chest 2006;129:899-904.

32. Resqueti VR, Gorostizza A, Gladis J, Lopez E, Clara PC, Guell R: Benefits of a home-based pulmonary rehabilitation program for patients with severe chronic obstructive pulmonary disease. Arch Bronconeumol 2007;43:599-604.

33. Freimark D, Schechter M, Schwadmenthal E, Tanne D, Elmaleh E, Shemesh Y, Motro M, Adler Y: Improved exercise tolerance and cardiac function in severe chronic heart failure patients undergoing a supervised exercise program. Int J Cardiol 2007;116:309-314. 
34. King JC, Nelson TR, Blankenship KJ, Turturro TC, Beck AJ: Rehabilitation team function and prescriptions, referrals, and order writing. In: DeLisa J, Gans B, Walsh N (eds): Physical Medicine and Rehabilitation: Principle \& Practice, 4th ed. Philadelphia: Lippincott Williams and Wilkins, 2005, p.1051

35. CMS/Medicare Learning Network: New Coverage Policies for Inpatient Rehabilitation Services; 2009 www.cms .gov/InpatientRehabFacPPS/Downloads/New Coverage_ Requirements_presentation.pdf. [Last accessed March 28, 2011.]

36. Medicare Benefit Policy Manual: Chapter 1-Inpatient Hospital Services Covered Under Part A; 2006 www.cms.gov/ InpatientRehabFacPPS/Downloads/Revised_Section_110_ MBP_Manual_DRAFT for Comment.pdf. [Last accessed March 28, 2011.]

37. Cruise CM, Lee MHM: Delivery of rehabilitation services to people with aging with disability. Phys Med Rehabil Clin N Am 2005;16:267-284.

38. Centers for Medicare and Medicaid Services: Medicare Hospice Benefits; 2010 www.medicare.gov/publications/ pubs/pdf/02154.pdf. [Last accessed March 28, 2011.]

39. Crooks V, Waller S, Smith T, Hahn TJ: The use of the Karnofsky performance scale in determining outcomes and risk in geriatric outpatients. I Gerontol 1991;46:139-144.

40. Mor V, Laliberte L, Morris JN: The Karnofsky performance status scale: An examination of its reliability and validity in a research setting. Cancer 1984;53:2002-2007.

41. Anderson F, Downing GM, Hill J: Palliative Performance Scale (PPS): A new tool. J Palliat Care 1996;12:5-11.

42. Oken MM, Creech RH, Tormey DC, Horton J, Davis TE, McFadden ET, Carbone PP: Toxicity and response criteria of the eastern cooperative oncology group. Am J Clin Oncol 1982;5:649-655.

43. Kaasa T, Wessel J: The Edmonton functional assessment tool: Further development and validation for use in palliative care. J Palliat Care 2001;17:5-11.

44. Bruera E, Kuehn N, Miller MJ, Selmser P, Macmillan K: The Edmonton symptom assessment system (ESAS): A simple method for the assessment of palliative care patients. $\underline{\mathrm{J} \text { Pal- }}$ liat Care 1991;7:6-9.

45. Chang VT, Hwang SS, Feuerman M: Validation of the Edmonton symptom assessment scale. Cancer 2000;88:2164-2171.

46. Katz S, Downs TD, Cash HR, Grotz RC: Progress in development of the index of ADL. Gerontol 1970;10:20-30.

47. Wallace M, Shelkey M: Katz index of independence in activities of daily living (ADL). Ann Longterm Care 2006; 14:26-27.

48. Lawton MP, Brody EM: Assessment of older people: Selfmaintaining and instrumental activities of daily living. Gerontol 1969;9:179-186.

49. Graf C: The Lawton instrumental activities of daily living (IADL) scale. Ann Long Term Care 2007;15:21-22.

50. Loewen SC, Anderson BA: Reliability of the modified motor assessment scale and the barthel index. Phys Ther 1988; 68:1077-1081.

51. Granger CV, Devis LS, Peters MC, Sherwood CC, Barrett JE: Stroke rehabilitation: analysis of repeated barthel index measures. Arch Phys Med Rehabil 1979;60:14-17.

52. Granger CV, Hamilton BB, Keith RA: Advances in functional assessment for medical rehabilitation. Top Geriatr Rehabil 1986;1:59-74.
53. Desrosiers J, Rochette A, Noreau L, Bravo G, Hebert R, Boutin C: Comparison of two functional independence scales with a participation measure in post-stroke rehabilitation. Arch Gerontol Geriatr 2003;37:157-172.

54. Berg KO, Wood-Dauphinee SL, Williams JL, Maki B: Measuring balance in the elderly: Validation of an instrument. Can J Public Health 1992;83(Suppl 2):S7-S11.

55. Tinetti ME: Performance-oriented assessment of mobility problems in elderly patients. J Am Geriatr Soc 1986;34:119-126.

56. Podsiadlo D, Richardson S: The timed "up \& go": A test of basic functional mobility for frail elderly persons. I Am Geriatr Soc 1991;39:142-148.

57. Kristensen MT, Foss NB, Kehlet H: Timed "up \& go" test as a falls predictor post hip fracture surgery. Phys Ther 2007;87: 25-30.

58. Enright PL: The six-minute walk test. Respir Care 2003; 48:783-785.

59. Frost M: The role of physical, occupational, and speech therapy in hospice: Patient empowerment. Am J Hosp Palliat Care 2001;18:397-402.

60. Ebel S, Langer K: The role of the physical therapist in hospice care. Am J Hosp Palliat Care 1993;10:32-35.

61. Charlton JE (ed): Core Curriculum for Professional Education in Pain. Seattle, WA: IASP Press, 2005.

62. O'Sullivan SB, Schmitz TJ: Physical rehabilitation: Assessment and treatment. In: Physical Medicine, 2nd ed. Philadelphia: F.A. Davis Co., 1988, p.248.

63. Shah SK: Cardiac rehabilitation In: DeLisa J, Gans B, Walsh N (eds): Physical Medicine and Rehabilitation: Principle $\mathcal{E}$ Practice, 4th ed. Philadelphia: Lippincott Williams and Wilkins, 2005, p.1811.

64. Bach JR: Rehabilitation of the patient with respiratory dysfunction. In: DeLisa J, Gans B, Walsh N (eds): Physical Medicine and Rehabilitation Principle \& Practice, 4th ed. Philadelphia: Lippincott Williams and Wilkins, 2005, p.1843.

65. Cooper J, Littlechild B: A study of occupational therapy interventions in oncology and palliative care. Int J Ther Rehabil 2004;11:329-333.

66. Pearson E, Todd JG, Futcher JM: How can occupational therapists measure outcomes in palliative care? $\underline{\text { Palliat Med }}$ 2007;21:477-485.

67. Pollens R: Role of speech-language pathologist in palliative hospice care. J Palliat Med 2004;7:694-702.

68. Goldsmith T: Ethical issues facing the speech-language pathologist in the acute care setting. ASHA Division 2 Neurophysiology and Neurogenic Speech and Language Disorders Newsletter, 1999 9(2), 20-23.

69. American Speech-Language-Hearing Association: Guidelines for the delivery of speech-language pathology and audiology services in home care. ASHA 1990;33:29-34.

Address correspondence to: Marcos L. Montagnini, M.D., FACP Division of Geriatric Medicine University of Michigan VA Ann Arbor GRECC (11-G) 2215 Fuller Road Ann Arbor, MI 48105

E-mail: mmontag@umich.edu 